\title{
The Recovery of the Ultrastructure of Hyperchromic Host Neurons Under the Influence of Fetal Neurotransplants
}

\author{
Vladimir N. Kleshchinov and Maria Alexandrova \\ Laboratory of Experimental Neurogenetics, N.I. Vavilov Institute of General Genetics, \\ USSR Academy of Sciences, Gubkin St., 3, 117809 Moscow, USSR
}

\section{SUMMARY}

Fetal neocortical transplants placed into a previously prepared cavity in the cortex of adult animals inhibited destructive processes in host neurons surrounding the place of injury. This was demonstrated by a gradual reduction in the number of hyperchromic and shrunken host neurons and the recovery of the ultrastructure of dystrophic cells which die as a result of neuronophagia or sclerosis in the absence of the transplants.

\section{KEY WORDS}

cortical lesion; hyperchromic neurons; fetal tranplants; recovery; dystrophic neurons

\section{INTRODUCTION}

Nervous tissue regeneration is one of the central problems in neurobiology. It is well known that spontaneous processes leading to normalization of disturbed functions sometimes occur in the damaged brain. For example, as a result of sprouting of neuronal axons, new synaptic connections may be established and result in the recovery of CNS functions. The regenerative processes of nerve cells are, however, restricted /4/. The successful development of neurotransplantation in recent years

Reprint address:

V.N. Kleshchinov

Laboratory of Experimental Neurogenetics

N.I. Vavilov Institute of General Genetics, USSR Academy of Sciences, Gubkin St., 3, 117809 Moscow, USSR has considerably extended the possibility of regeneration in the damaged brain $/ 5 /$.

Brain damage is often accompanied by the appearance of dystrophic neurons. It is generally accepted that dystrophic nerve cells (shrunken neurons) are dying or dead cells /25/. However, developing embryonic nervous tissue (ENT) can prevent degenerative processes in the host brain $/ 19,22 /$ and promote the recovery of the structure and function of neurons after damage $/ 1,7,17 /$. In our previous work, it was shown that ENT transplantation into a recently prepared cavity reduced the hyperchromic and shrunken neurons which normally appeared around the wound in the host brain (i.e., prevented the degenerative processes following injury). Moreover, in some nerve cells, partial differentiation /10/, replicative DNA synthesis and mitotic figures were observed $/ 11,12,18 /$. The purpose of the present work was to study the state of hyperchromic and shrunken neurons appearing around a mechanically-induced brain wound at various times after ENT transplantation.

\section{MATERIALS AND METHODS}

Transplantation of 15-day-old embryonic ENT into adult female Wistar rats (160-200 g) was carried out according to the following scheme. An aspirative cavity $\left(5 \mathrm{~mm}^{3}\right)$ was made in the sensorimotor cortex under hexenal-ether anesthesia. The cavity was then covered with gelfoam. After 10 days an embryonic neocortical transplant was placed into the cavity. The animals were then transcardially perfused with $2.5 \%$ glutaraldehyde $/ 0.1 \%$ cacodylate buffer $(\mathrm{pH}$ $=7.4$ ) either 10 days following injury or $4,7,13$, or 30 days after ENT transplantation $(n=3$ per group). The tissue was post-fixed for $1.5 \mathrm{~h}$ in 
ethanol at increasing concentrations and embedded in araldite. For electron microscopy, the tissue was first examined using semithin sections stained with methylene blue. Ultrathin sections were prepared on an LKB ultratome and viewed under an EM-420 electron microscope.

\section{RESULTS}

Analyis of semithin sections of the host sensorimotor cortex 10 days following surgery revealed neurons in various stages of hyperchromia, ranging from cells with poorly pronounced hyperchromia to dark shrunken neurons. This was accompanied by an acute edema, astrogliosis and narrowing of blood vessel lumina. The largest number of dark cells was observed in cortical layers V-VI (Fig. 1).

Electron microscopic examination revealed that the nuclei of normochromic neurons contained small conglomerations of condensed chromatin and reduced aggregates of interchromatin granules (Fig. 2). In the cytoplasm of these cells, the endoplasmic reticulum cisterns were expanded and did not form parallel aggregates. The mitochondria exhibited focal zones of clearing and damaged cristae. This pattern of neural damage was primarily evident in small to medium-sized nonpyramidal neurons.

In some cells with a poorly expressed hyperchromia, the nuclei had irregular profiles with deep invaginations and contained large nucleoli, small conglomerations of condensed chromatin and a set of RNA particles characteristic of neuronal nuclei (Fig. 3). No pronounced destructive changes were observed in the cytoplasm. Hyperchromia occurred mainly as a result of the diminution of the cytoplasm and a compacted distribution of free polysomes. These cells were usually surrounded by swollen astrocyte processes.

The dark shrunken neurons had reduced volume compared to normochromic neurons (Fig. 4). The nuclei of these cells were irregularly shaped with deep invaginations together with conglomerations of condensed chromatin, an increased number of interchromatin granules (both free and clustered) and an increased number of perichromatin granules. The nucleoli were small and had a poorly distinguishable ultrastructure. The cytoplasm was densely packed with dissociated polysomes and the lumina of the endoplasmic reticulum cisterns and the perinuclear space were slightly widened. Vacuoles also occurred in the cytoplasm due to the destruction of mitochondrial cristae.

In summary, 10 days following cortical aspiration, a variety of changes were observed in nerve cells around the cavity. These changes included the appearance of blocks of condensed chromatin in neuronal nuclei, accumulation of interchromatin and perichromatin granules, dissociation of cytoplasmic polysomes and destructive processes in mitochondria. These changes were associated with a neuropilar edema, narrowing of blood vessels and a subsequent acidosis in the host tissue.

The ENT transplants survived and developed well after transplantation. Within 4 days, most cells looked lighter than normochromic neurons and there were occasional examples of hyperchromic and shrunken neurons (Fig. 5). Electron microscopy at this time demonstrated a great variety of changes in nerve cells. In the nuclei of hyperchromic neurons there were small blocks of condensed chromatin and loose fibers on the borders (Fig. 6). Aggregates of interchromatin and perichromatin granules were sharply reduced. Within the cytoplasm, the cisterns of the endoplasmic reticulum were only slightly expanded and the majority of free ribosomes were assembled into polysomes. Other neurons had normochromic nuclei. A distinctive feature of these hyperchromic neurons was the presence of vacuoles in the cytoplasm due to swollen mitochondria with damaged cristae and increased cytoplasmic electron density (Fig. 7).

At 4 days post ENT transplant, the majority of neurons were pale with large nuclei and numerous invaginations (Fig. 8). The nuclei contained small blocks of condensed chromatin with few RNA particles and vacuoles of various sizes. In the cytoplasm of these cells were free polysomes, single endoplasmic reticulum cisterns, small mitochondria and occasional lysosomes. Bundles of filaments were observed in the bodies of astroglial cells in the host tissue surrounding the developing transplant (Fig. 9).

Seven days after ENT transplantation, no hy- 


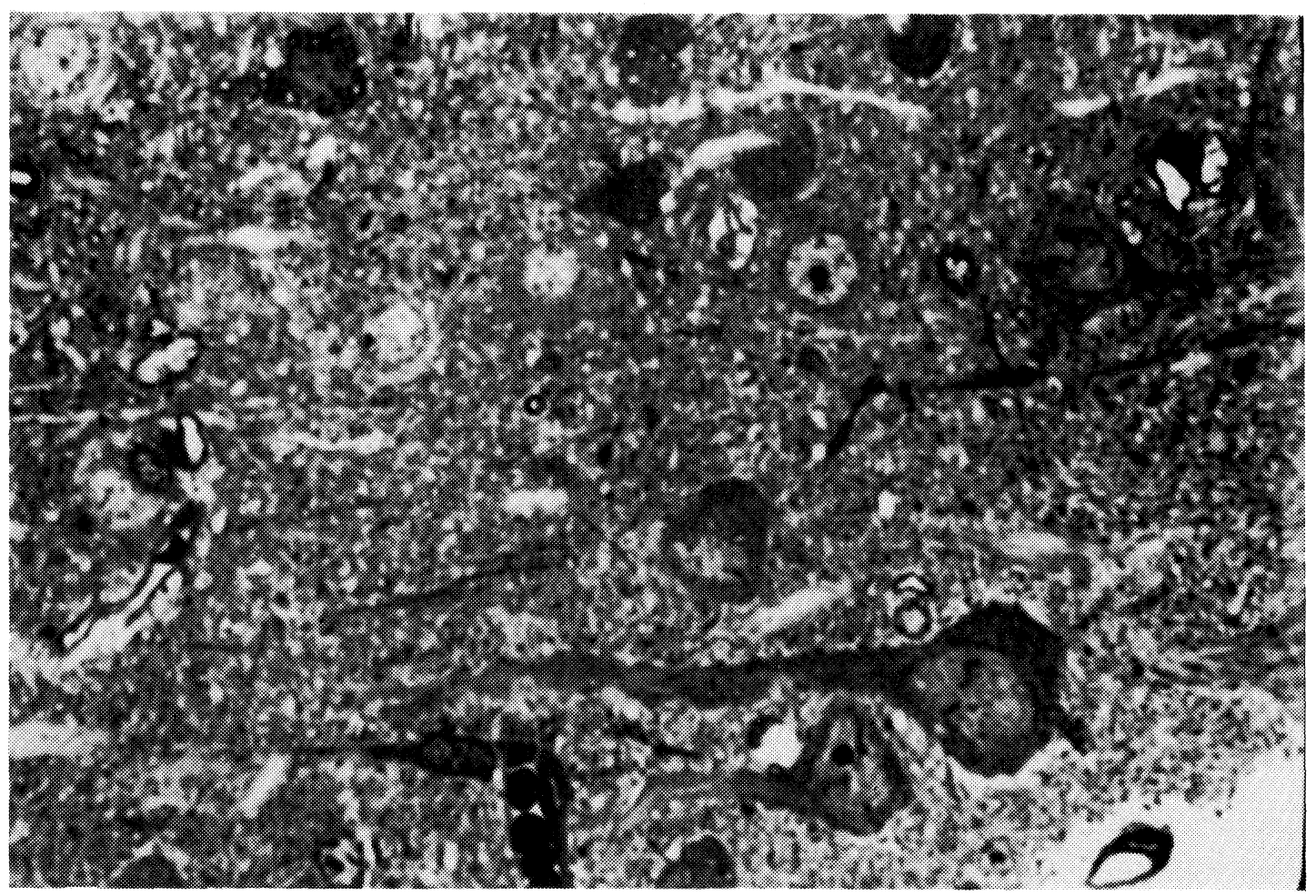

Fig. 1: A semithin section of rat brain sensorimotor cortex around an artificial cavity on the 10th day after nervous tissue aspiration illustrating the presence of hyperchromic neurons. $400 \mathrm{x}$.

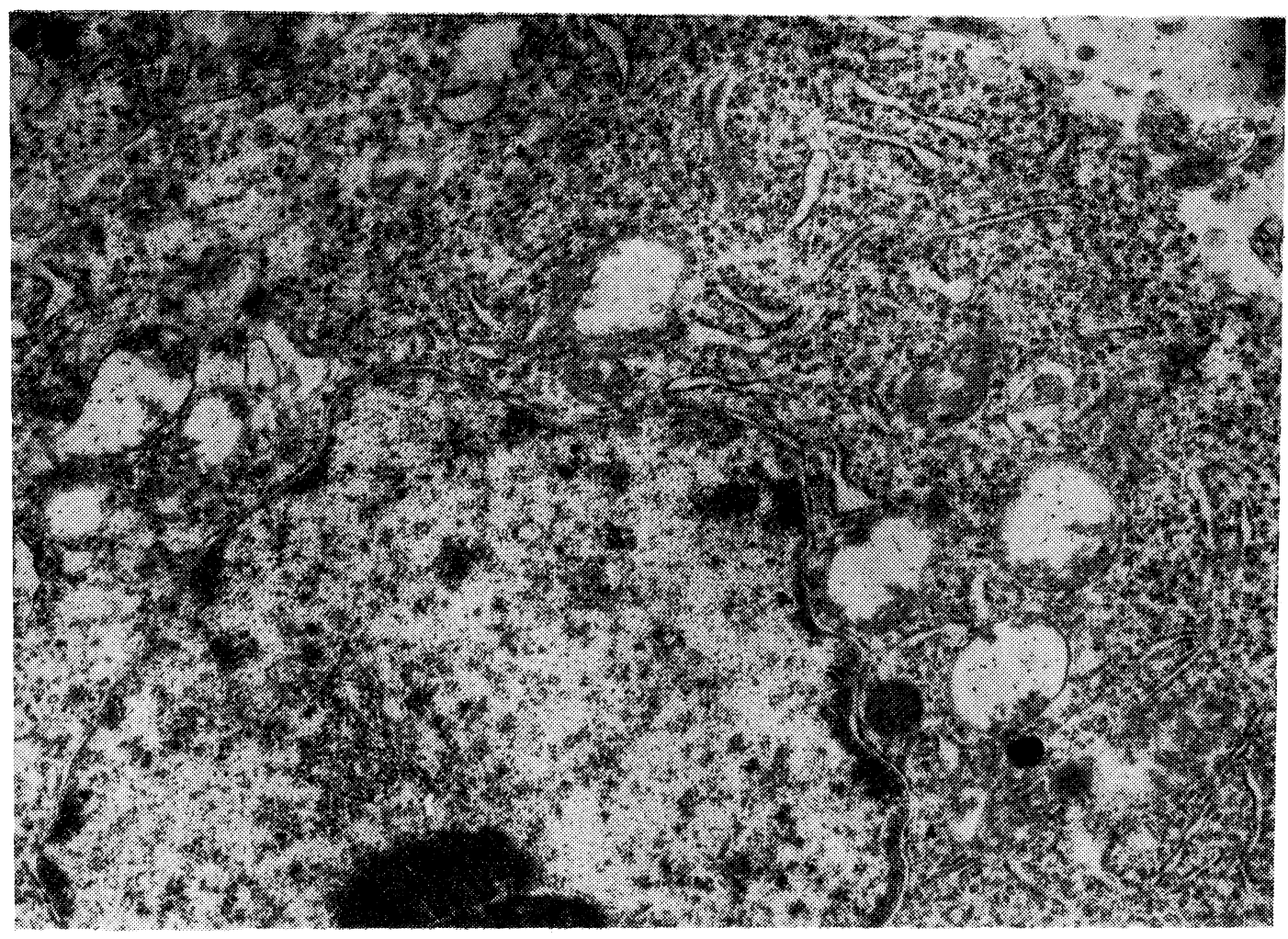

Fig. 2: Host brain normochromic neuron in the close vicinity of the cavity on the 10th day after aspiration. Note the blocks of condensed chromatin in the nucleus, expansion of endoplasmic reticulum cisterns, perinuclear cytoplasmic space and mitochondria. 16,000 $\mathrm{x}$. 


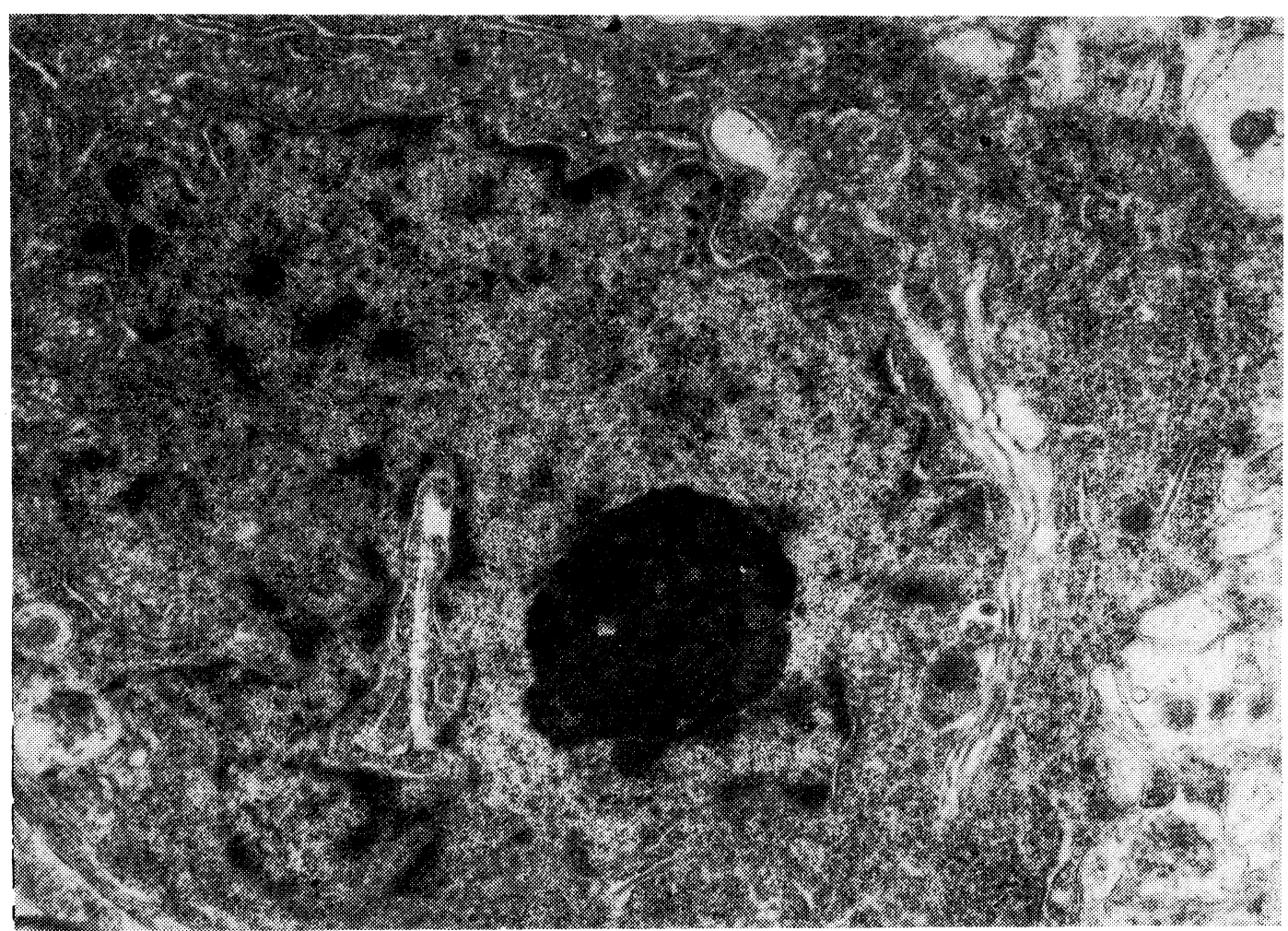

Fig. 3: Host brain hyperchromic neuron from the region of damage around an artificial cavity without pronounced destructive changes. $17,000 \mathrm{x}$.

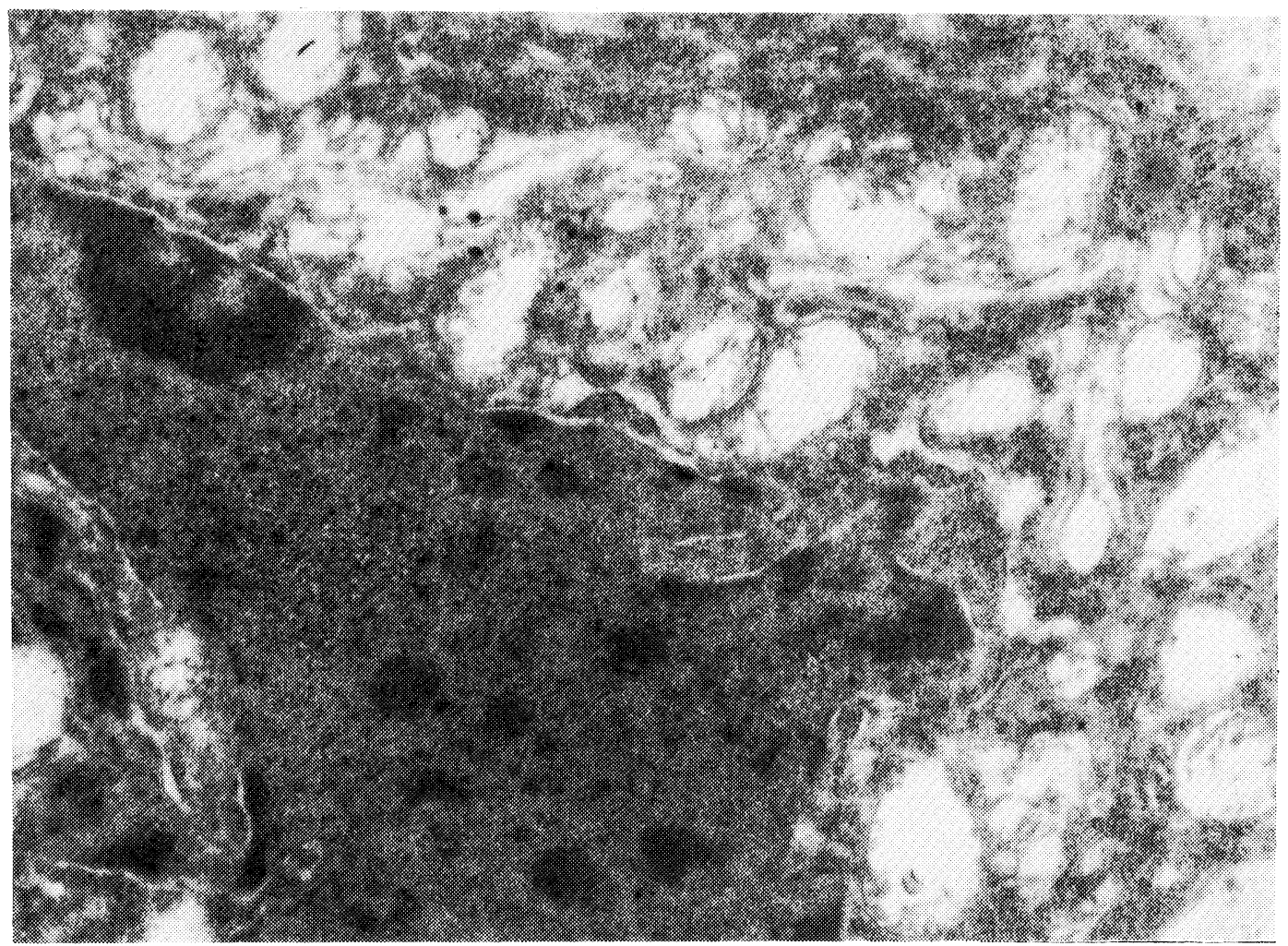

Fig. 4: Host brain shrunken neuron from the region of damage in the vicinity of the cavity illustrating chromatin in the nucleus, increased number of interchromatin and perichromatin granules, and destructive changes in mitochondria. 16,000 x. 
a

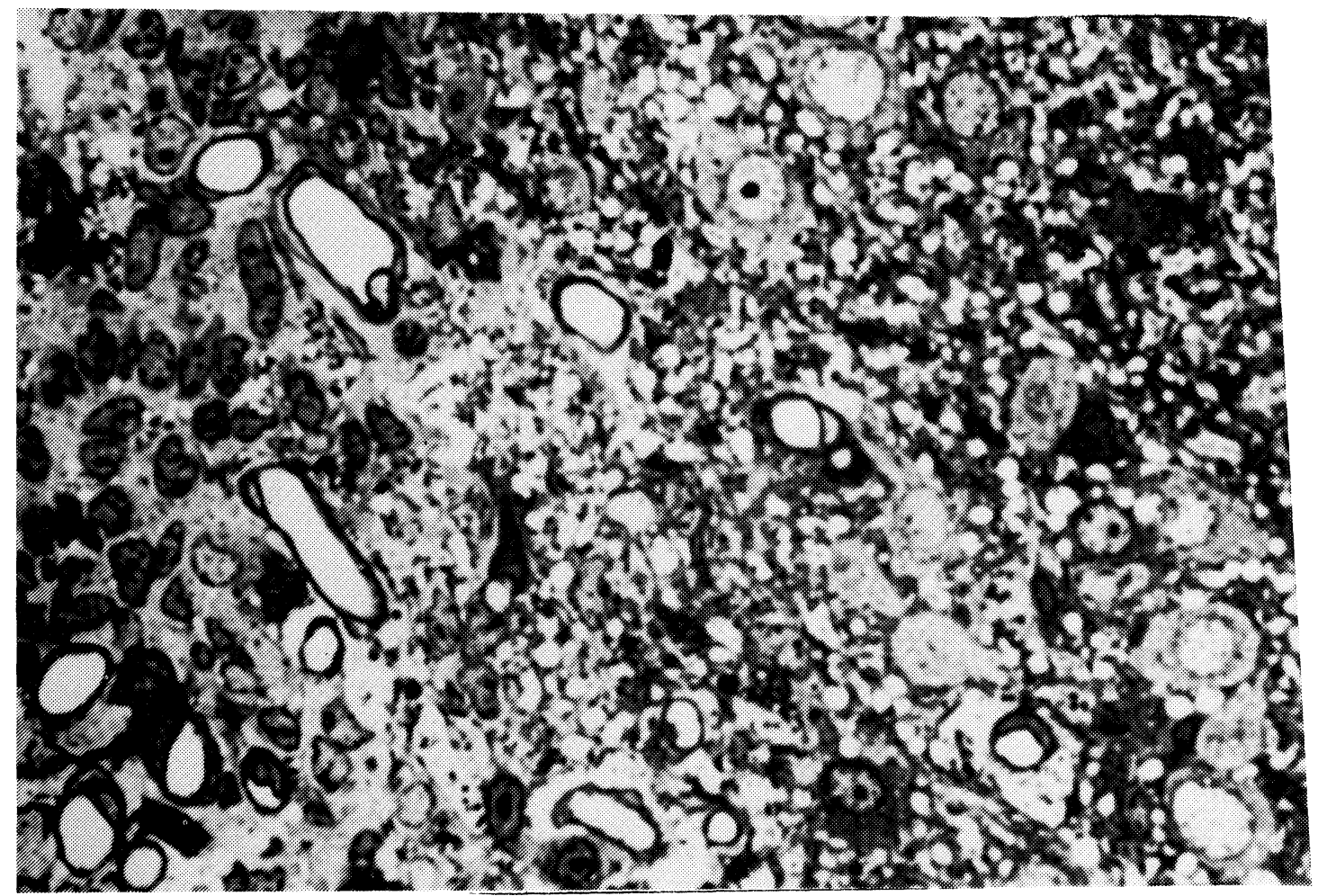

b

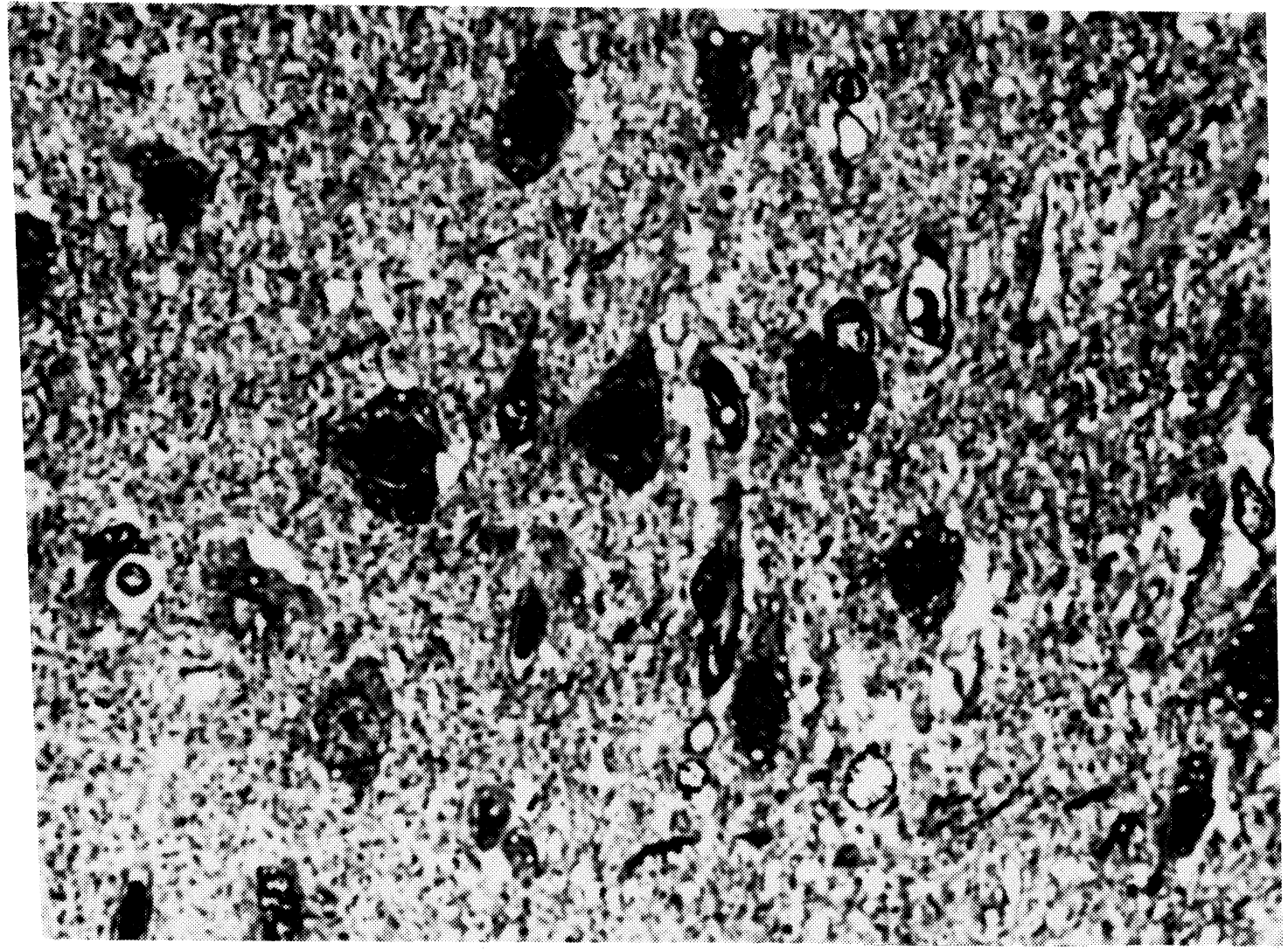

Fig. 5: Semithin sections of rat brain sensorimotor cortex on the 10th day after nervous tissue aspiration and the 4th day after ENT transplantation. Note the presence of few hyperchromic and several light nerve cells (a). There are several hyperchromic neurons in the injured brain without a graft on the 14th day (b). $400 \mathrm{x}$. 


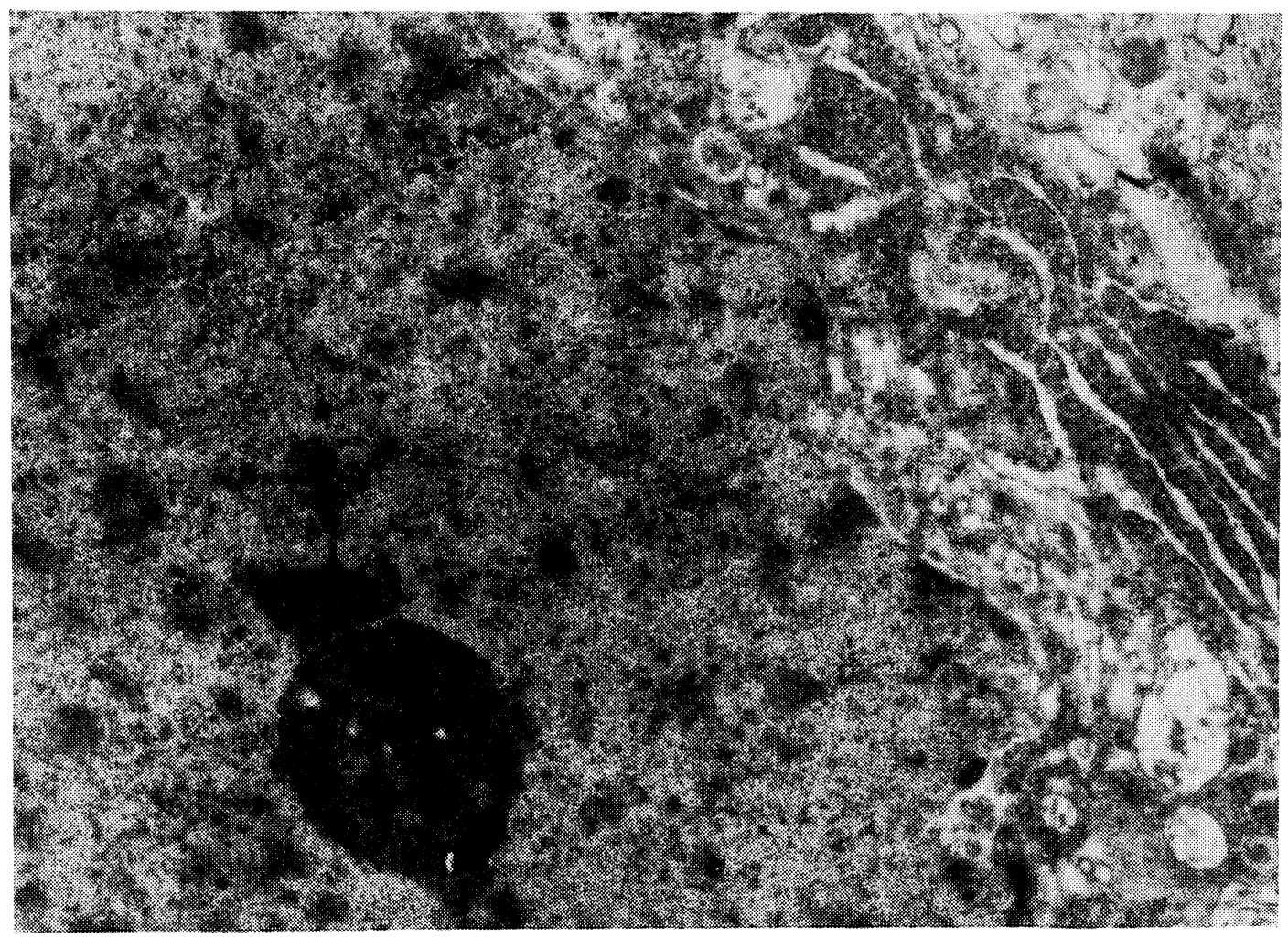

Fig. 6: Host brain cortex hyperchromic neuron on the 4th day after ENT transplantation demonstrating the beginning of recovery of the cell ultrastructure. $18,000 \mathrm{x}$.

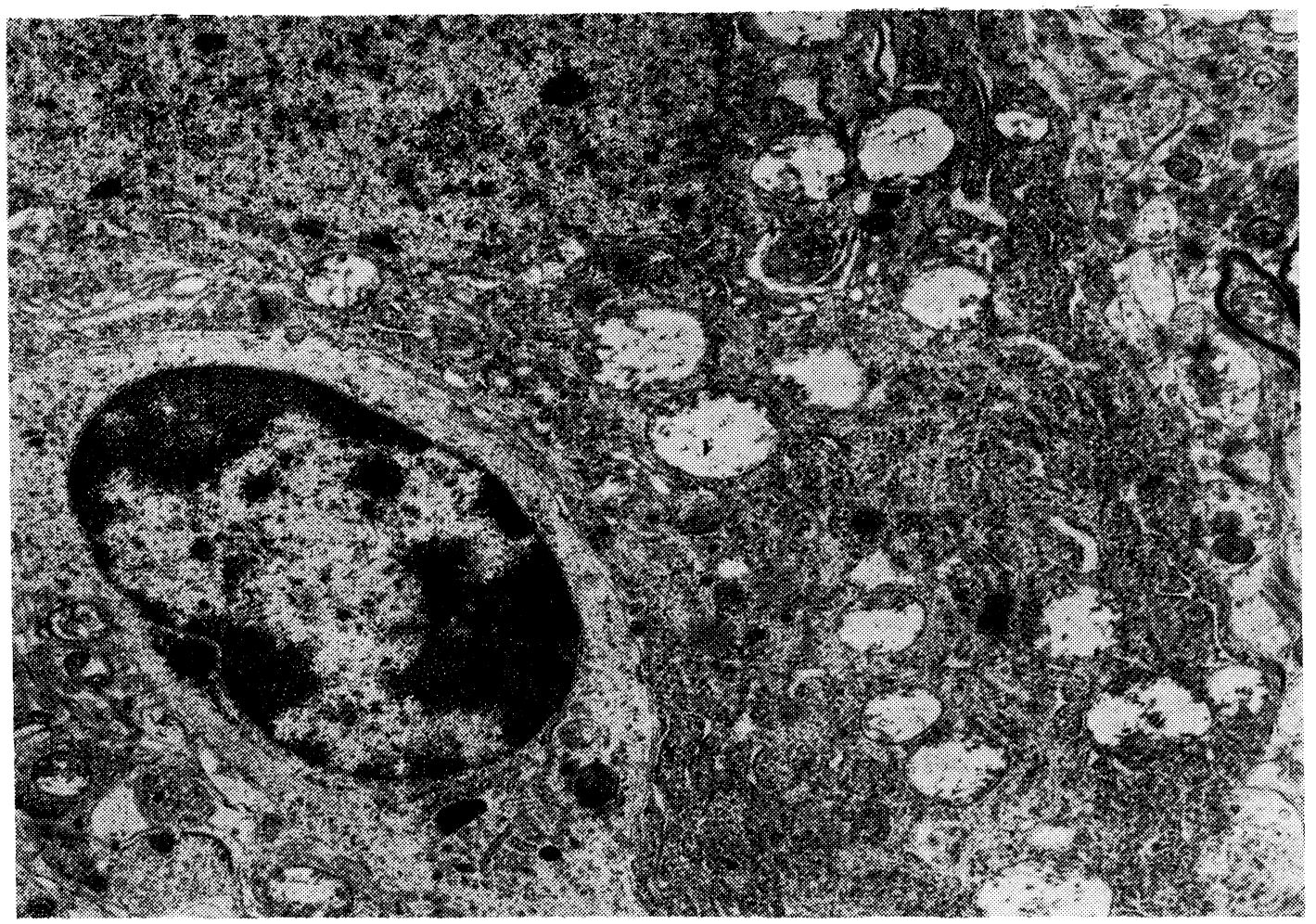

Fig. 7: Host brain cortex hyperchromic neuron on the 4th day after ENT transplantation. Note the recovery of the cell ultrastructure, vacuolation of mitochondria in the cytoplasm. 12,000 x. 


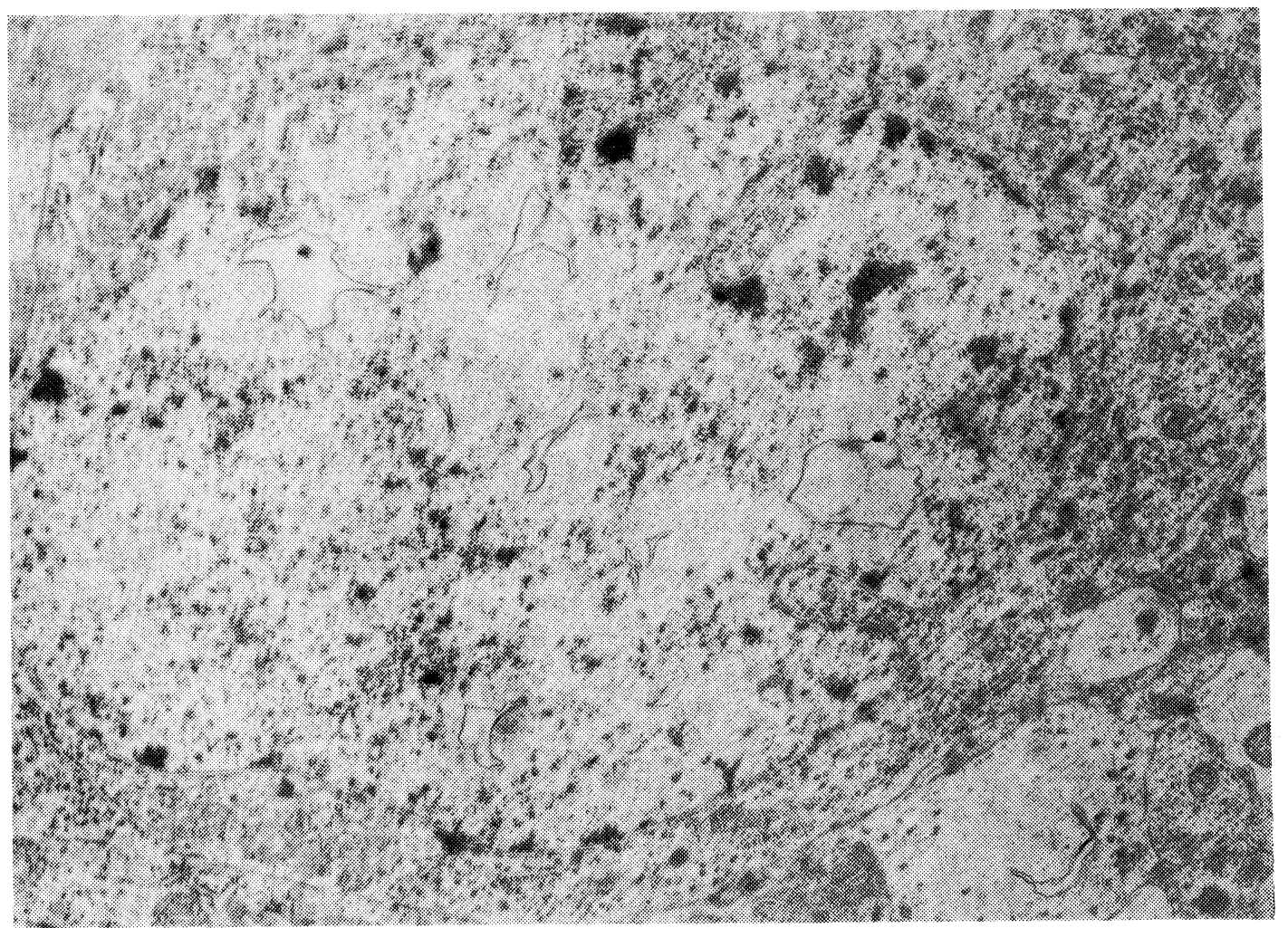

Fig. 8: Host brain hypochromic neuron on the 4th day after ENT transplantation illustrating vacuoles in the nucleus. $11,000 \mathrm{x}$.

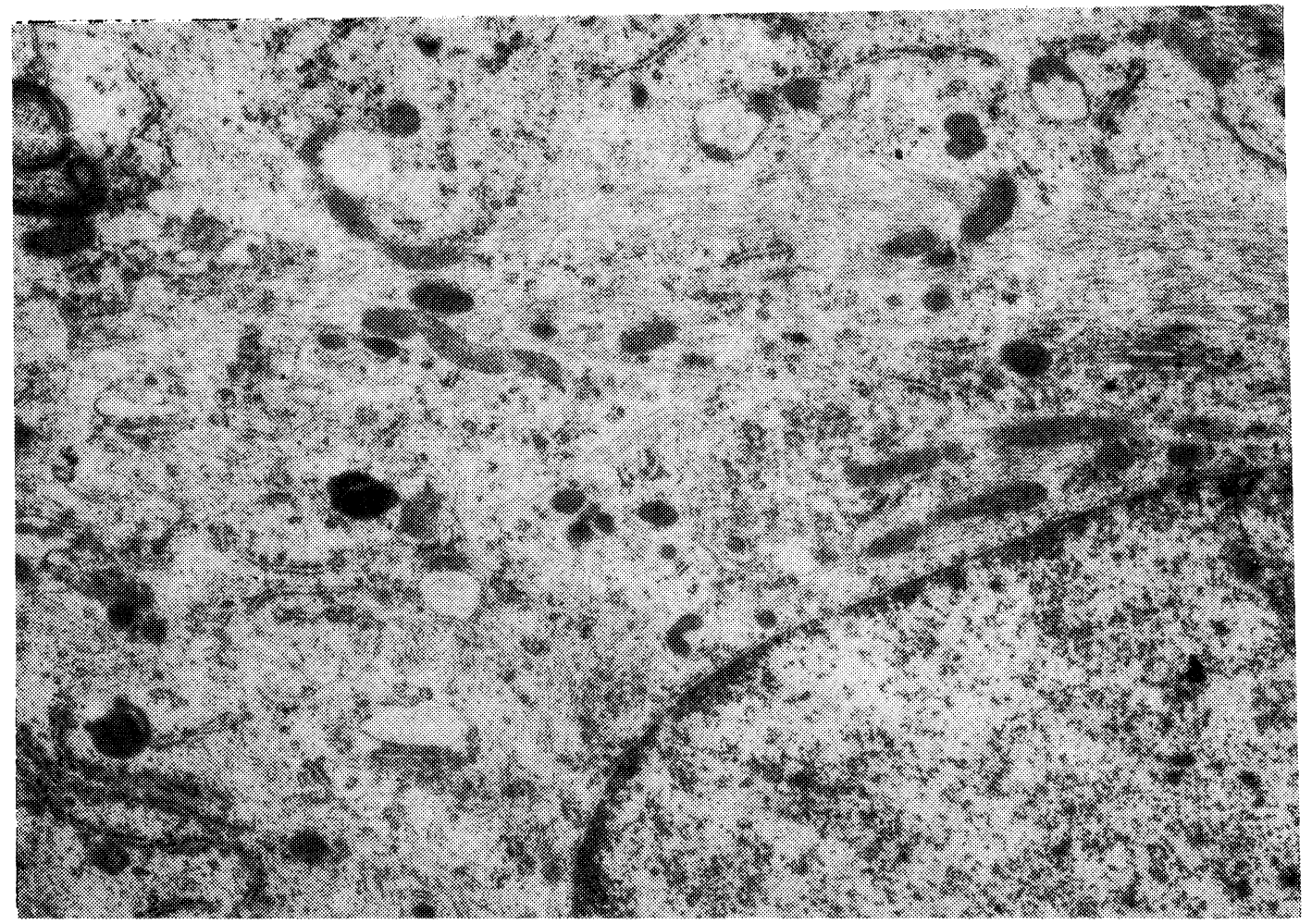

Fig. 9: Host brain astroglia on the 4th day after ENT transplantation demonstrating the appearance of bundles of filaments in the cell body. 20,000 x. 
perchromic cells were found in the surrounding tissue. On the contrary, most neurons had an electron-lucent karyoplasm, a small number of condensed chromatin blocks and a minimal number of RNA particles (Fig. 10). Vacuoles were also found in the nuclei. In the cytoplasm, free polysomes were not as prevalent as they were in pale cells at 4 days post implantation. The length of individual endoplasmic reticulum cisterns and their number were considerably larger, but there were no structural characteristics of neurons including the chromophilic substance. Consistently present in the cytoplasm were lysosomes, small lipid droplets, a large number of multivesicular bodies of different size and single swollen endoplasmic cisterns (Fig. 11). At this time, large numbers of fibrils were also detected in the bodies and processes of the host brain astrocyte cells.

At 10-15 days after ENT transplantation, host neurons exhibited a normal electron density. The nuclear ultrastructure of most nerve cells appeared normal. In the cytoplasm, there were numerous free polysomes, single endoplasmic reticulum cisterns with ribosomes, and randomly distributed mitochondria generally with a dense matrix. There were also normal synaptic contacts within the host tissue and nerve cells containing foci of clearing in which broken membrane remnants and amorphous material could be observed (Fig. 12). Processes and bodies of astrocytes with densely packed fibrillar material were also observed.

Thirty days after ENT transplantation, no hyperchromic neurons were observed in the host tissue. The majority of nerve cells had a normal structure with the exception of a few neurons which contained foci of clearing in the nuclei. These foci included a floccular material, single membranes and an occasional unidentified granular component (Fig. 13).

\section{DISCUSSION}

A developing fetal neocortical transplant placed into a previously prepared cavity in the brain of an adult animal inhibited destructive processes in host neurons surrounding the site of injury. This was expressed primarily as a general reduction in the number of hyperchromic and shrunken host brain neurons and in the recovery of the ultrastructural properties of dystrophic cells which normally die through neurophagia or sclerosis in the absence of a transplant.

The present results on the recovery of the ultrastructure of shrunken neurons are in good agreement with previous reports of the positive effects of ENT transplanted into the CNS. For example: (1) Our previous work demonstrated that ENT transplants prevented the death of neurons in the cortex and hippocampus following hypoxia /1,17/; (2) Atrophy of thalamic tissue $/ 19,24 /$, cholinergic neurons in the nucleus basalis 123 / and neocortical damage induced by kainic acid $/ 22$ / is prevented by prior transplantation of ENT; (3) Transplanted thalamic or tectal tissue prevents optic nerve degeneration $/ 20 /$ and embryonic retinal cell implants prevent the dystrophy of retinal cells /14/, and finally (4) Fetal tissue transplants promote recovery of motor functions in rats following contusion-induced neural trauma $/ 22 /$.

The mechanism by which embryonic tissue exerts its protective effects is unclear but might relate to the production and release of trophic factors by the transplanted tissue. Following brain damage there is a gradient of trophic activity within the damaged region which stimulates the survival and growth of transplanted tissue $/ 3,16 /$. Moreover, the exogenous administration of trophic factors promotes the survival of neurons and produces functional recovery. Nerve growth factor injected into the brain of aged rats not only minimized the age-related atrophy of cholinergic neurons but promoted recovery of cognitive performance in these same animals /6/. Accordingly, the present results may reflect the ability of specific embryonic trophic factors released by the ENT to influence the regenerative processes of damaged neurons $/ 8,9 /$.

It is generally believed that shrunken nerve cells are irreversibly dystrophic and will ultimately die. However, the present study indicates that the cellular dystrophy which occurs following neural damage is indeed reversible. While regenerating neurons exhibited various structural abnormalities, including breakage of portions of the endoplasmic reticulum cisterns and mitochondria, and the appearance of lipid inclusion and vacuolization of nuclei, these 


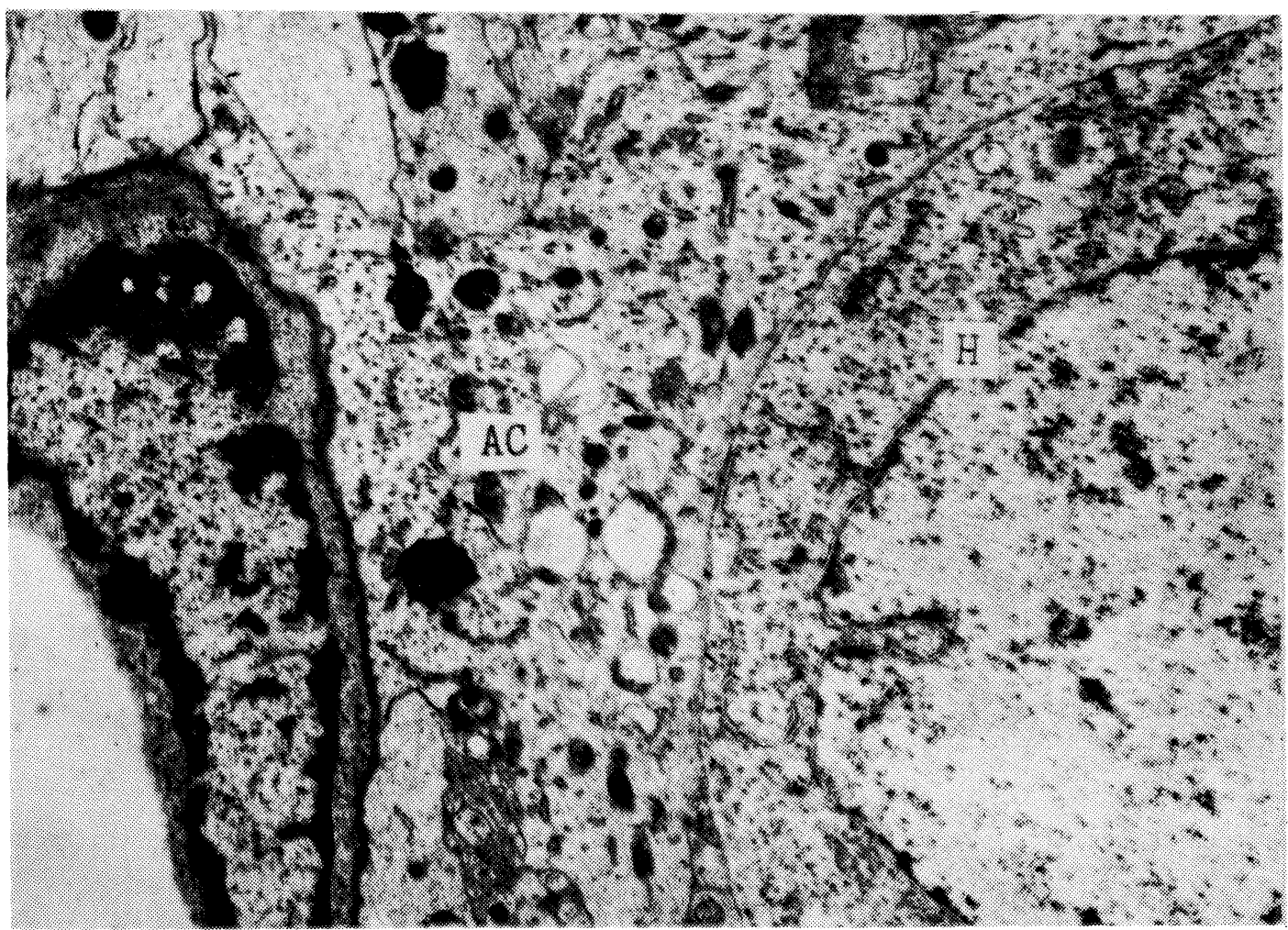

Fig. 10: Host nervous tissue fragment on the 7th day after ENT transplantation. $H=$ hyperchromic neuron, $A C=$ astrocytic processes with filaments and lipid inclusions. 11,000 x.

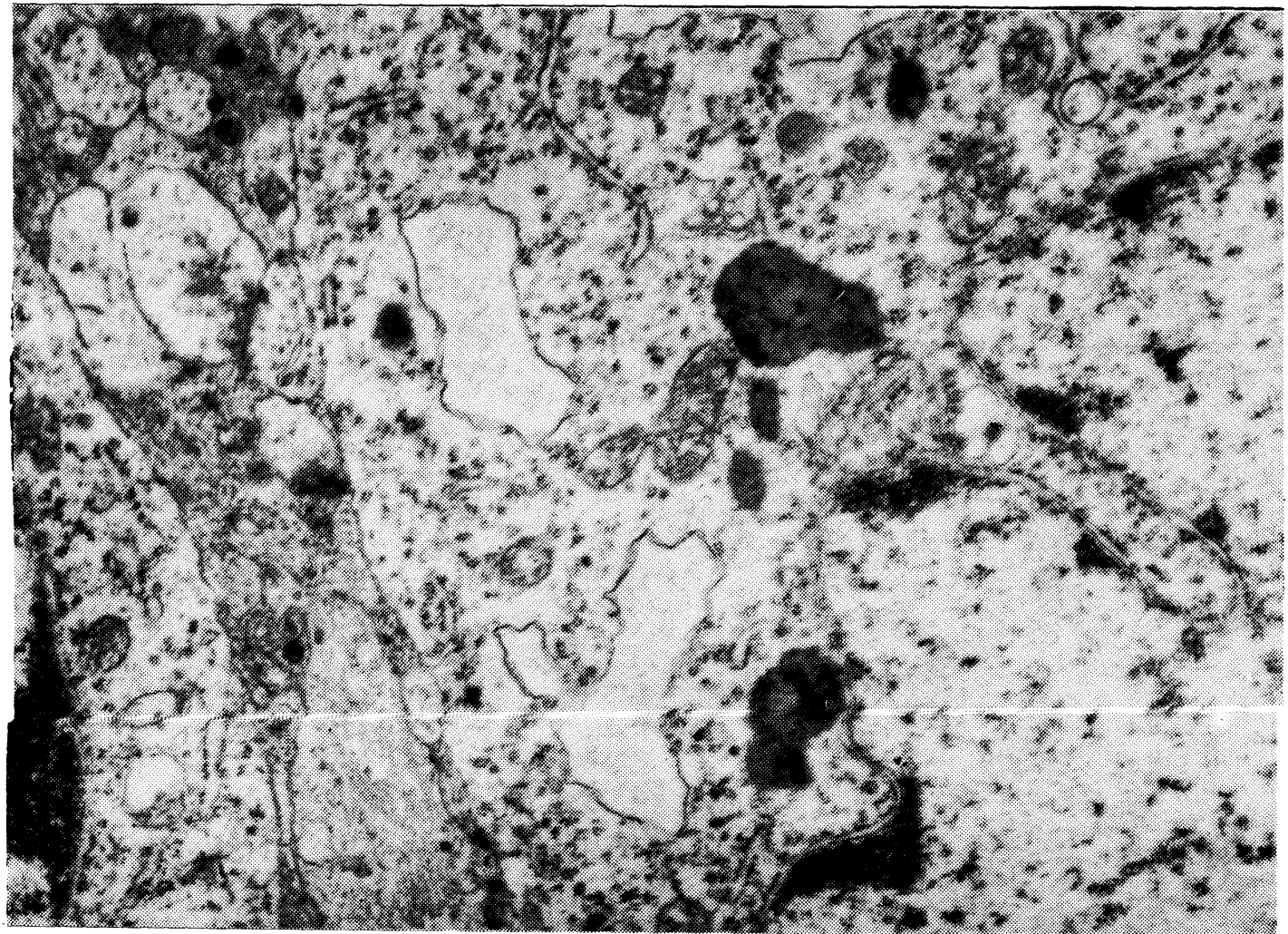

Fig. 11: Host brain neuron fragment on the 7th day after ENT transplantation. A few swollen endoplasmic reticulum cisterns, lysosomes and lipid droplets are observed. 22,000 x. 


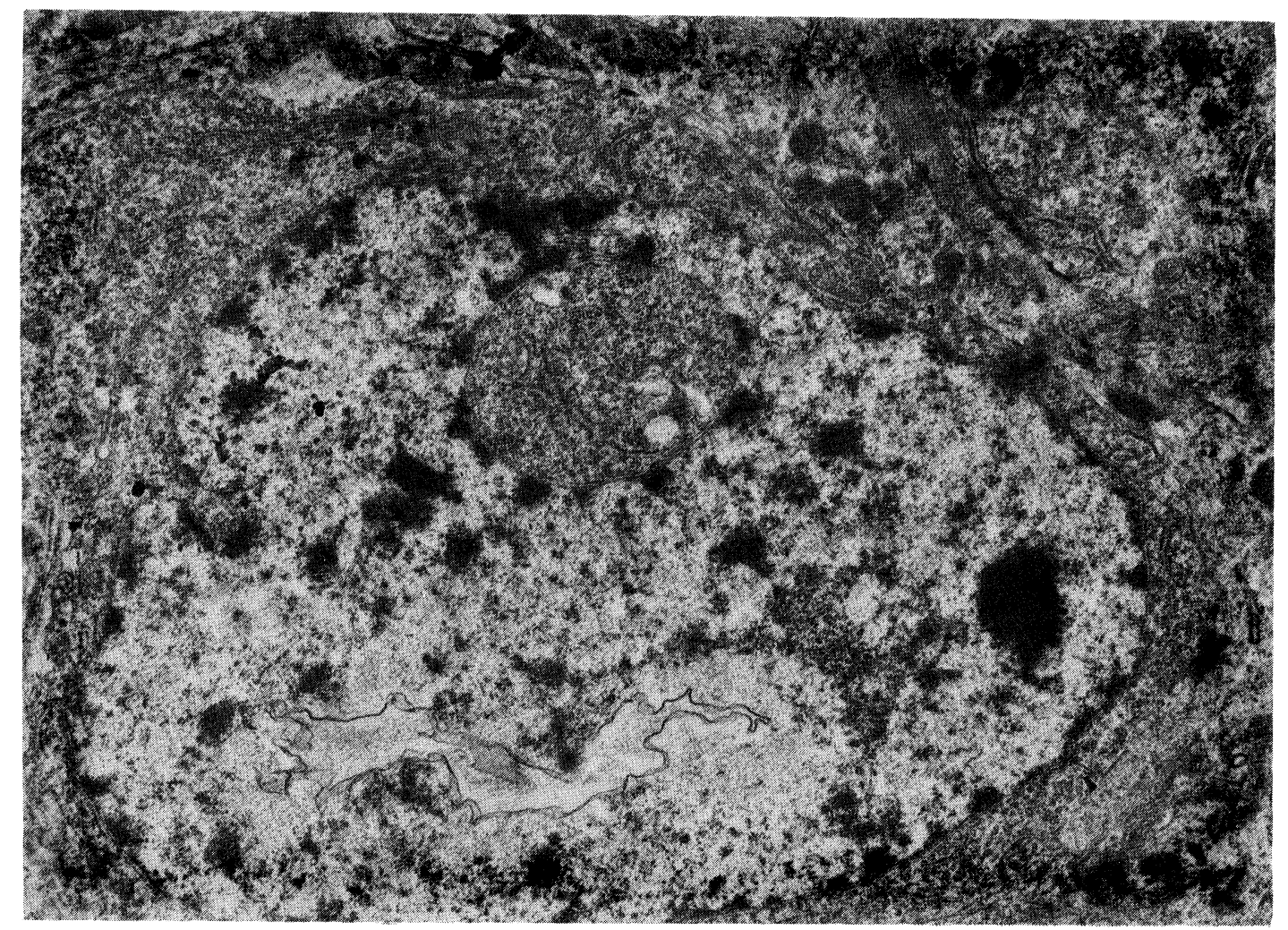

Fig. 12: Host brain cortical neuron on the 15th day after ENT transplantation showing the foci of clearing in the nucleus. $13,000 \mathrm{x}$.

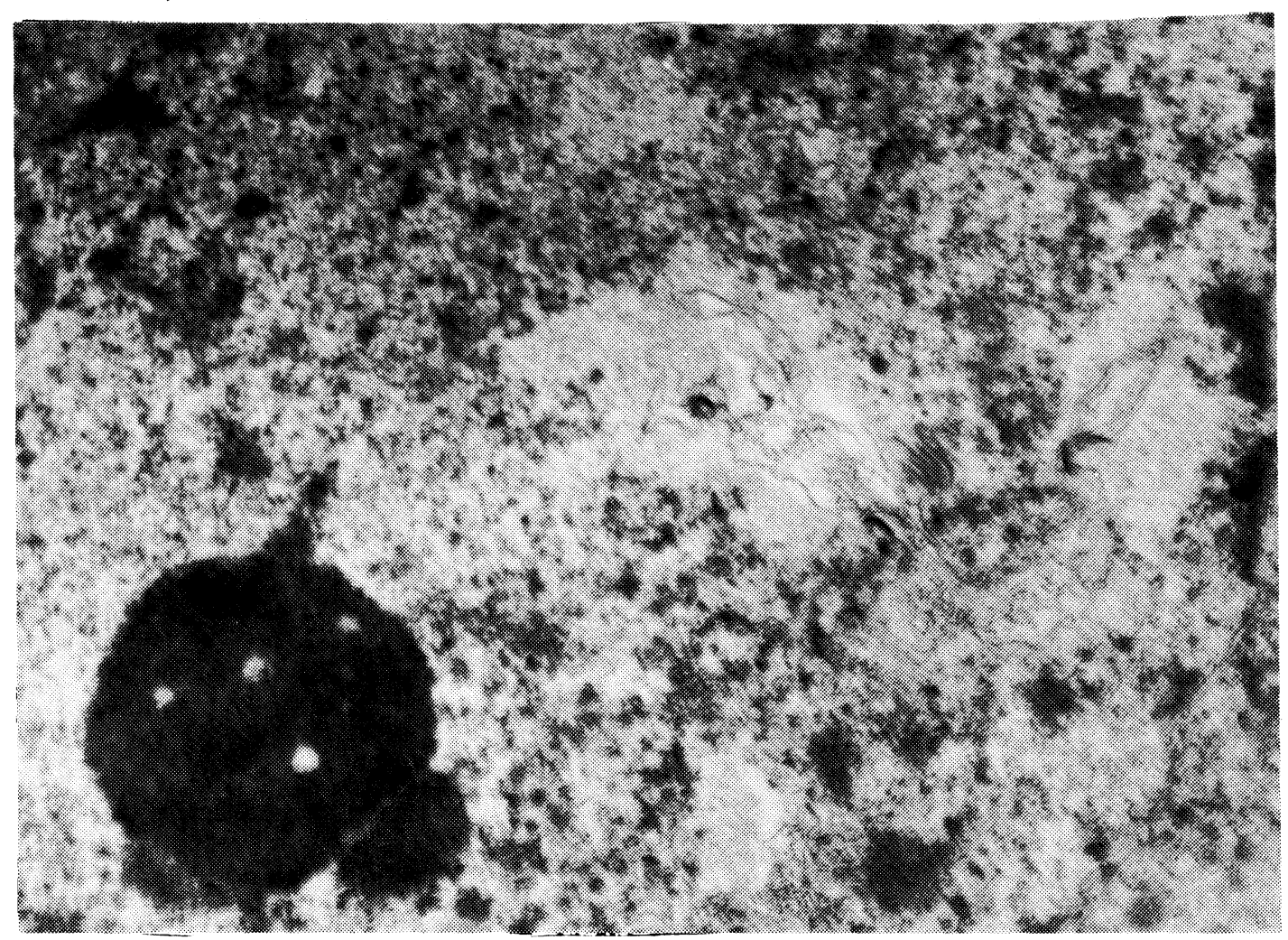

Fig. 13: Host brain cortex neuron on the 30th day after ENT transplantation. Note the foci of clearing in the nucleus together with a floccular material, loose membranes and granular component. 26,000 x. 
neurons were largely indistinguishable from, normal cells within 30 days. It appears, then, that under specific conditions (i.e., presence of developing fetal tissue), adult CNS tissue possesses a robust regenerative capacity.

\section{ACKNOWLEDGEMENT}

The authors appreciate the assistance of Dr. Dwaine F. Emerich in editing and proofreading the manuscript.

\section{REFERENCES}

1. Alexandrova MA. Transplantation of embryo brain tissue into the brain of adult rats, intact and exposed to hypoxia. In: Bjorklund A, Stenevi U (eds), Neural Grafting in Mammalian CNS. Amsterdam-New YorkOxford: Elsevier, 1985; pp 243-247.

2. Bogolepov NN. Brain ultrastructure by hypoxia. Moscow: Meditsina 1979; 168.

3. Cotman CW, Kesslak JP. The role of trophic factors in behavioral recovery and integration of transplants. In: Gash DM, Sladek JR (eds), Transplantation into the Mammalian CNS. Amsterdam-New York-Oxford: Elsevier, 1988; 78: pp 311-319.

4. Cotman CW, Nieto-Sampedro M, Harris EW. Synapse replacement in the nervous system of adult vertebrates. Physiol Rev 1981; 61: 684-784.

5. Das GD, Wallace RB (eds) Neural Transplantation and Regeneration. New York-Berlin-HeidelbergTokyo: Springer-Verlag, 1986; 330.

6. Fischer W, Chen KS, Cage FH, Bjorklund A. NGF can reverse age-dependent neuronal atrophy in the cholinergic system of the forebrain. Restor Neurol Neurosci 1989; 1: 20.

7. Gravina A, Domenici L, Berardi N, Galli L, Maffei L. Transplantation of embryonic nervous tissue prevents the responses of rat retinal ganglion cells after section of the optic nerve. Exp Brain Res 1990; 80: 631-640.

8. Hofer MM, Barge YA. Brain-derived neurotrophic factor prevents neural death in vivo. Nature 1988; 331: 261-262.

9. Isacson $\mathrm{O}$, Wictorin $\mathrm{K}$, Fisher $\mathrm{W}$, Sofroniev MW, Bjorklund A. Fetal cortical cell suspension graft to the excitotoxically lesioned neocortex: anatomical and trophic interactions. In: Gash DM, Sladek JR (eds), Transplantation into the Mammalian CNS. Amsterdam-New York-Oxford: Elsevier, 1988; pp. 1326.

10. Kleshchinov VN. Changes of recipient brain neurons around the transplant of embryonic nervous tissue. Ontogenes 1989; 19: 216-220.

11. Kleshchinov VN. Replicative DNA synthesis in the adult rat brain cells after transplantation of embryonic nervous tissue. Doklady Acad Sci USSR 1989; 309:
468-470.

12. Kleshchinov VN. Ultrastructure of mitotically dividing cells with signs of neurons in the rat brain. Archiv Anat 1989; 96: 41-44.

13. Kleshchinov VN, Koydan EI, Kolomeets NS. Characteristics of hyperchromic neurons from the focus of local cortical destruction. Bull Exp Biol 1983; 96: 104106.

14. Laedtke TW, Turner JE. Embryonic retinal grafts have a beneficial effect on the damaged host retina. Brain Res 1989; 500: 61-66.

15. Manthorpe M, Nieto-Sampedro $M$, Skaper SD, Lewis ER, Barbin G, Longo FM, Cotman CW, Varon S. Neuotrophic activity in brain wounds of the developing rat. Correlation with implant survival in the wound cavity. Brain Res 1983; 267: 47-56.

16. Nieto-Sampedro $M$, Manthorpe $M$, Barbin G, Varon $\mathrm{S}$, Cotman CW. Injury-induced neuronotrophic activity in adult rat brain: correlation with survival of delayed implants in the wound cavity. J Neurosci 1983; 11: 2219-2229.

17. Polezhaev LV, Alexandrova MA, Girman SV. Normalization of dystrophic brain cortex neurons after hypoxia and transplantation of embryonic nervous tissue in rats. J Hirnforsch 1986; 27: 501-513.

18. Polezhaev LV, Alexandrova MA, Kleshchinov VN. DNA synthesis and mitotic division of cortical neurons in adult rats upon intrabrain transplantation of embryonic nerve tissue. J Hirnforsch 1988; 29: 673-681.

19. Sharp FR, Gonzalez MF. Fetal cortical transplants ameliorate thalamic atrophy ipsilateral to neonatal frontal cortex lesion. Neurosci Lett 1986; 71: 247-251.

20. Sievers J, Hausmann B, Berry M. Fetal brain promotes axon regeneration and survival of adult rat retinal ganglion cells. In: Gash DM, Sladek JR (eds), Transplantation into the Mammalian CNS. AmsterdamNew York-Oxford: Elsevier, 1988; pp 371-376.

21. Soares H, McIntosh T. Fetal CNS transplants following traumatic brain injury. Restor Neurol Neurosci 1989; 1: 20.

22. Sofroniew MV, Isacson O, Bjorklund A. Cortical grafts prevent atrophy of cholinergic basal nucleus neurons induced by excitotoxic cortical damage. Brain Res 1986; 378: 409-415.

23. Sorensen JC, Wanner-Oleson H, Tonder N, Danielsen $\mathrm{E}$, Castro AJ, Zimmer J. Basal forebrain neurons can reinnervate grafts of fetal frontal cortex placed in frontal cortex lesions of adult rats. Restor Neurol Neurosci 1989; 1: 36.

24. Sorensen JC, Zimmer J, Castro AJ. Fetal cortical transplants reduce the thalamic atrophy induced by frontal cortical lesions in newborn rats. Neurosci Lett 1989; 1: 33-38.

25. Zhabotinsky UM. Normal and pathological morphology of the neuron. Leningrad: Meditsina 1965; 200. 

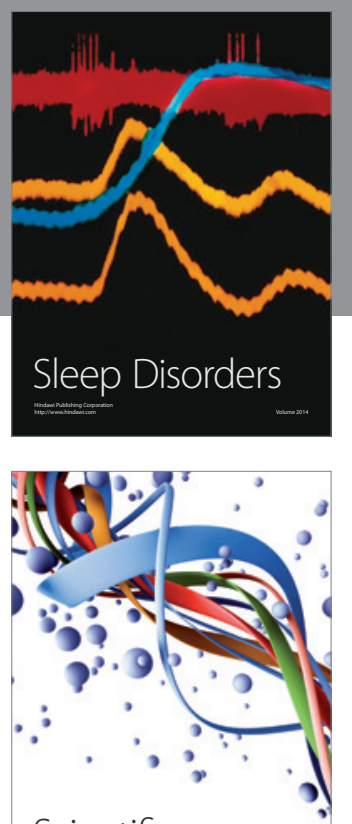

Scientifica
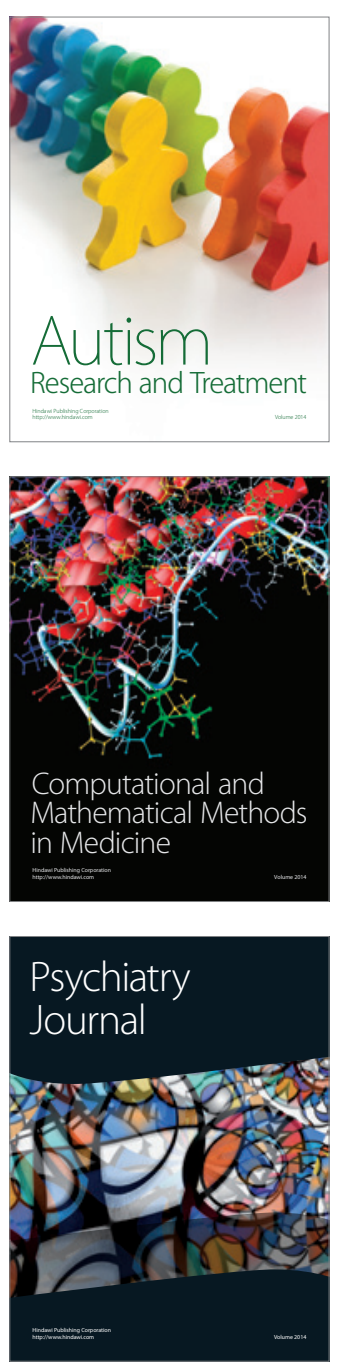
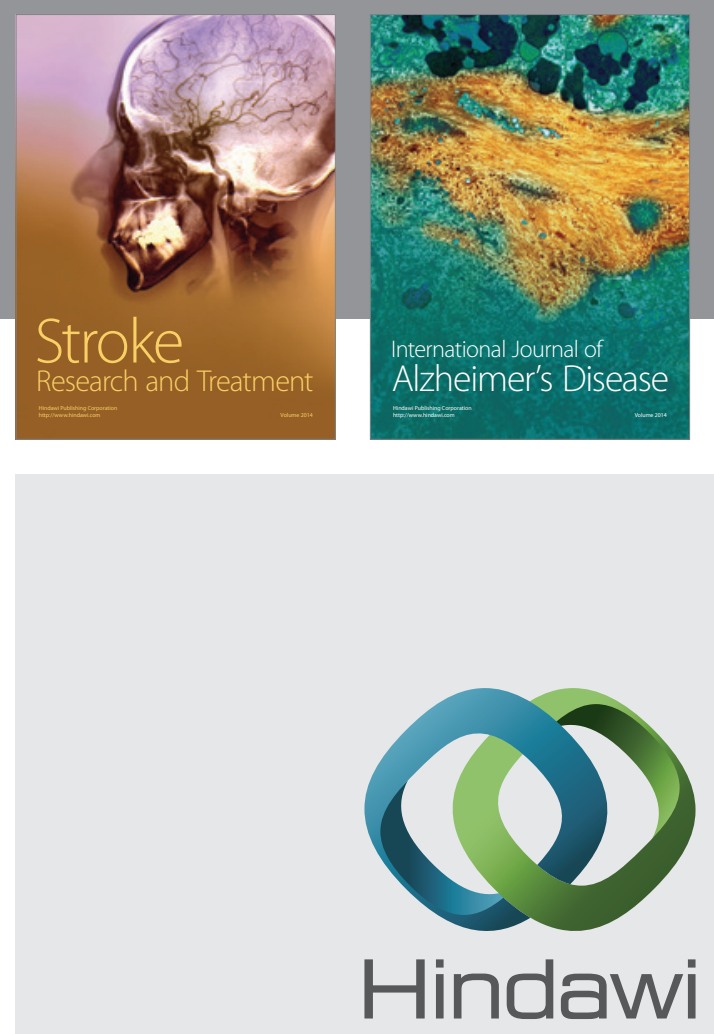

Submit your manuscripts at

http://www.hindawi.com
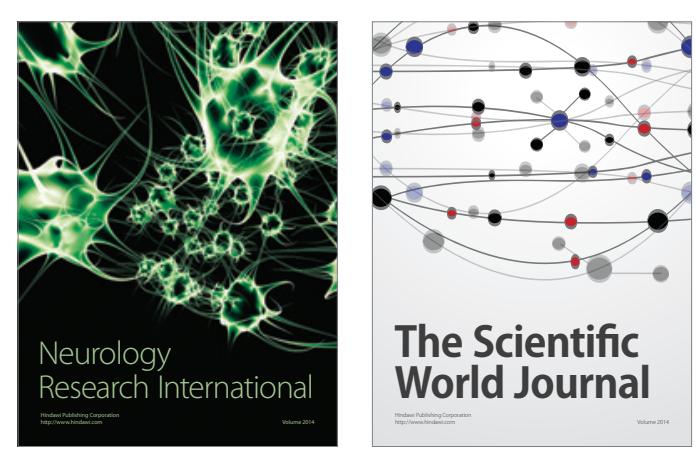

The Scientific World Journal

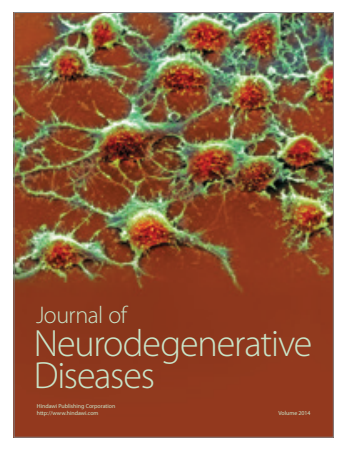

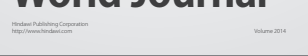

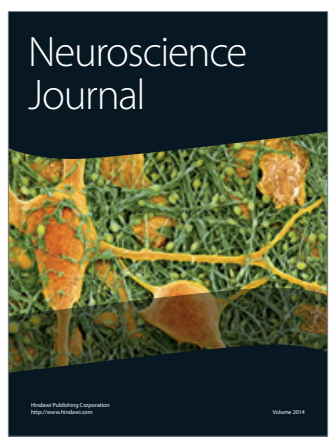

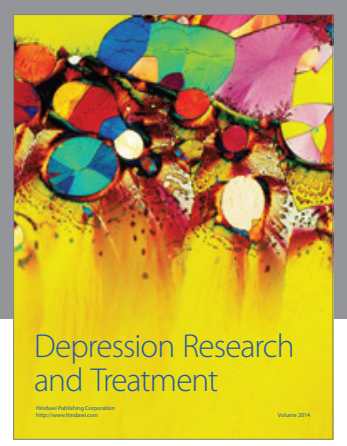
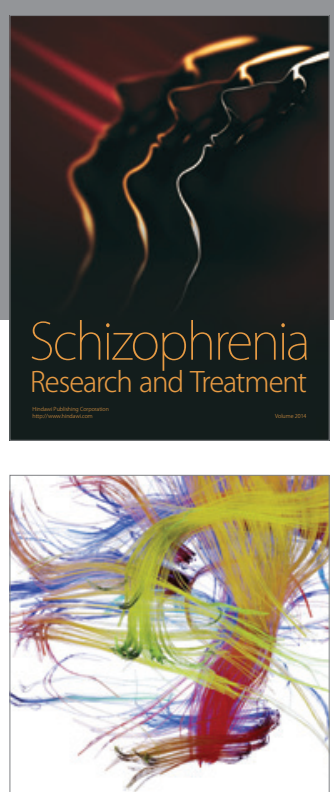

Brain Science

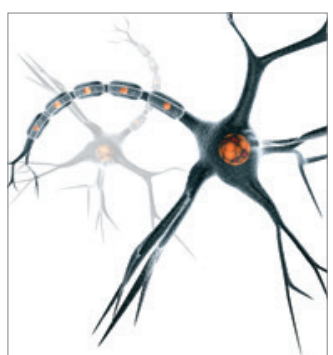

Neural Plasticity
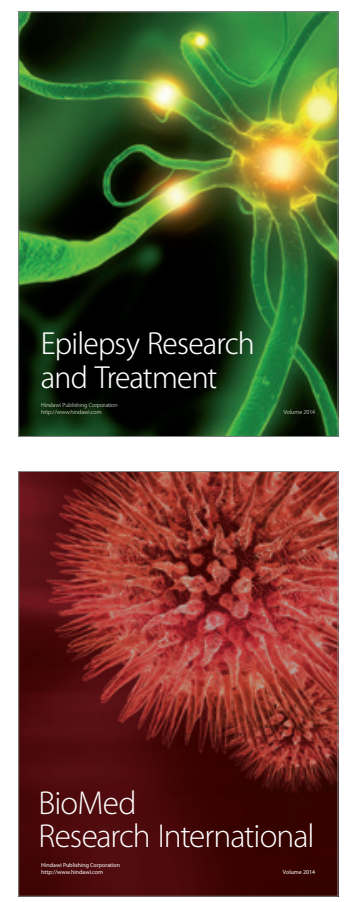

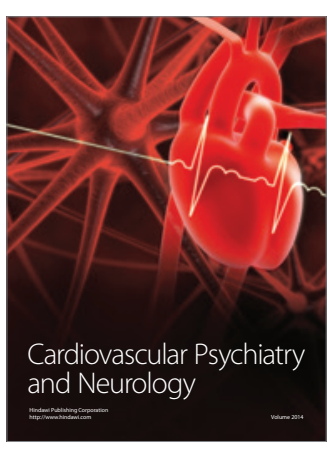

Parkinson's

Disease
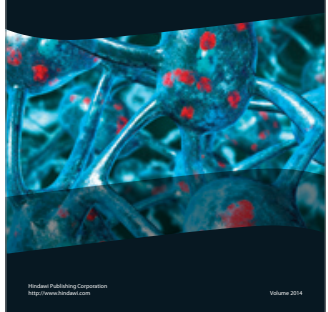